\title{
Mechanically Robust BiSbTe Alloys with Superior Thermoelectric Performance: A Case Study of Stable Hierarchical Nanostructured Thermoelectric Materials
}

\author{
Yun Zheng, Qiang Zhang, Xianli Su,* Hongyao Xie, Shengcheng Shu, Tianle Chen, \\ Gangjian Tan, Yonggao Yan, Xinfeng Tang,* Ctirad Uher, and G. Jeffrey Snyder
}

Bismuth telluride based thermoelectric materials have been commercialized for a wide range of applications in power generation and refrigeration. However, the poor machinability and susceptibility to brittle fracturing of commercial ingots often impose significant limitations on the manufacturing process and durability of thermoelectric devices. In this study, melt spinning combined with a plasma-activated sintering (MS-PAS) method is employed for commercial p-type zone-melted $(\mathrm{ZM})$ ingots of $\mathrm{Bi}_{0.5} \mathrm{Sb}_{1.5} \mathrm{Te}_{3}$. This fast synthesis approach achieves hierarchical structures and in-situ nanoscale precipitates, resulting in the simultaneous improvement of the thermoelectric performance and the mechanical properties. Benefitting from a strong suppression of the lattice thermal conductivity, a peak ZT of 1.22 is achieved at $340 \mathrm{~K}$ in MS-PAS synthesized structures, representing about a $40 \%$ enhancement over that of ZM ingots. Moreover, MS-PAS specimens with hierarchical structures exhibit superior machinability and mechanical properties with an almost $30 \%$ enhancement in their fracture toughness, combined with an eightfold and a factor of six increase in the compressive and flexural strength, respectively. Accompanied by an excellent thermal stability up to $200^{\circ} \mathrm{C}$ for the MS-PAS synthesized samples, the MS-PAS technique demonstrates great potential for mass production and large-scale applications of $\mathrm{Bi}_{2} \mathrm{Te}_{3}$ related thermoelectrics. attention during the past two decades because of its zero emission advantage, no moving parts, and low maintenance cost. $^{[1,2]}$ It is well known that the conversion efficiency of a TE module depends mainly on the dimensionless figure of merit of the TE elements in the thermoelectric equation $Z T=\alpha^{2} \sigma \mathrm{T} / \kappa$, where $\alpha$, $\sigma, \kappa$, and $T$ are the Seebeck coefficient, electrical conductivity, thermal conductivity, and absolute temperature, respectively. ${ }^{[3-5]}$ The thermal conductivity, $\kappa=\kappa_{\mathrm{e}}$ $+\kappa_{\mathrm{L}}$, consists of two components, namely $\kappa_{\mathrm{e}}$ and $\kappa_{\mathrm{L}}$, which are the carrier and lattice thermal conductivity, respectively. Therefore, a relatively high power factor $\left(\alpha^{2} \sigma\right)$ together with a significant reduction in the thermal conductivity will contribute to an improved performance of TE devices. ${ }^{[4]}$ The most effective approaches involve nanostructuring, ${ }^{[6]}$ which incorporates in-situ or extrinsic nanoprecipitates by mechanical alloying, compositional inhomogeneities, melt spinning, etc., which all lead to a dramatic suppression of the lattice thermal conductivity.

\section{Introduction}

Thermoelectric (TE) energy conversion, one of the most environmentally friendly technologies, has attracted worldwide

Y. Zheng, Q. Zhang, X. Su, H. Xie, S. Shu, T. Chen,

G. Tan, ${ }^{[+]}$Y. Yan, Prof. X. Tang

State Key Laboratory of Advanced Technology

for Materials Synthesis and Processing

Wuhan University of Technology

Wuhan 430070, China

E-mail: suxianli@whut.edu.cn; tangxf@whut.edu.cn

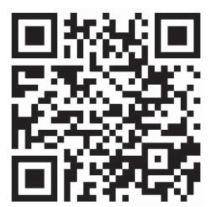

Prof. C. Uher

Department of Physics

University of Michigan

Ann Arbor, MI 48109, USA

Dr. G. J. Snyder

Department of Materials Science

California Institute of Technology

Pasadena, CA 91125, USA

${ }^{[+]}$Present address: Department of Chemistry, Northwestern University, Evanston, IL, 60208, USA.

DOI: 10.1002/aenm.201401391
Although numerous novel families of thermoelectric materials have been discovered in the past few years, bismuth telluride based alloys maintain their position as the leading stateof-the-art TE materials with values of $Z T$ approximating $1 .{ }^{[2,7}$ These materials have been successfully scaled up for commercial applications, such as power generation from waste industrial heat and spot cooling. ${ }^{[3,8]}$ In general, zone melting (ZM) has long been proven to be one of the most effective and promising methods for large-scale industrial production. ${ }^{[9]}$ Although ZM leads to a favorable TE performance along the crystal growth direction, there are still a lot of problems associated with ZM ingots, such as their low yield and mechanical instability in the manufacturing and assembling processes due to the easy cleavage along basal planes, thereby making their fabrication into microdevices very difficult. ${ }^{[3,5,7]}$ The idea of hierarchical configurations originated from natural materials such as nacre and bamboo that exhibit ultra-high fracture toughness due to their structural hierarchy ranging from the nanoscale to the macroscale. ${ }^{[10]}$ Recently, extensive effort has been devoted to design artificial materials that involve hierarchical constituents to achieve specific or enhanced physical properties. ${ }^{[1]}$ 
Exceptionally large figures of merit have been obtained with hierarchical architectures that provide for effective phonon scattering over a broad range of phonon frequencies. ${ }^{[12,13]}$ An instrumental example in this regard is a recently reported study on PbTe-based materials. ${ }^{[12]}$ A maximum $Z T$ of around 2.2 was achieved at $915 \mathrm{~K}$ in p-type PbTe doped with 4 mol\% $\mathrm{SrTe}$, which could be ascribed to the integrated phonon scattering from the all-scale hierarchical structure spanning from the atomic scale to the mesoscale. Moreover, substantial investigations have extended to incorporating hierarchical structures to increase the crack growth resistance, thus enhancing the mechanical properties in metals, ceramics, nanomaterials and polymer composites. ${ }^{[14]}$ It is noteworthy that melt spinning combined with rapid sintering has been developed as a fast and facile technique to introduce multiscale nanostructures and/or coherent interfaces in order to improve the TE performance. ${ }^{[15-19]}$ In this regard, it would be interesting to find out if such hierarchical architectures, constructed by melt spinning and rapid sintering, can be implemented to simultaneously improve the thermoelectric and mechanical properties. Moreover, melt spinning has long been regarded as an effective and promising method for the mass production of magnetic and amorphous alloys, ${ }^{[20]}$ fibers, ${ }^{[21,22]}$ composites, ${ }^{[21]}$ and carbon nanotubes. ${ }^{[23]}$ Hence, it should be easily implemented for the synthesis of thermoelectric materials on a large scale.

Due to the brittle nature of most chalcogenide-based TE materials, it is of equal importance to improve the machinability and mechanical properties for the manufacturing and long-term reliability of TE devices. To date, extensive research concerning their mechanical performance has been carried out on a series of TE compounds such as skutterudites, ${ }^{[18,24,25]}$ AgPbSbTe (LAST) alloys, ${ }^{[26]} \mathrm{YbAl}_{3},{ }^{[27]} \mathrm{La}_{3} \mathrm{Te}_{4},{ }^{[28]} \mathrm{Mg}_{2}$ (Si, $\left.\mathrm{Sn}\right),{ }^{[29]}$ $\mathrm{PbTe},{ }^{[30]}$ oxides, ${ }^{[31]}$ bismuth tellurides, ${ }^{[19,32-34]}$ mineral tetrahedrites, ${ }^{[35]} \mathrm{Zn}_{4} \mathrm{Sb}_{3},{ }^{[16,36]}$ etc. Most of the published literature has focused on investigating the composition dependence of the elastic properties by measuring sound velocities, and on roomtemperature mechanical properties typified by the Vickers hardness, fracture toughness, bending or compressive strengths, which all provided useful information on estimates of the thermal stress distribution. However, the key factor here is the actual strength of the TE elements within the operating temperature range, especially when analyzing the stability and reliability in response to high temperatures. ${ }^{[33,37,38]}$

This work demonstrates a facile technique of MS-PAS to achieve hierarchical structures and in-situ nanoprecipitates in p-type $\mathrm{Bi}_{0.5} \mathrm{Sb}_{1.5} \mathrm{Te}_{3}$ alloys, which exhibit superior thermoelectric and mechanical properties and machinability in comparison to ZM ingots. Combined with an excellent thermal stability, MS-PAS renders alloys that demonstrate great potential in commercial applications.

\section{Results and Discussion}

\subsection{XRD and Microstructure Analysis}

X-ray diffraction (XRD) analysis was performed perpendicular to the sintering pressure direction of the MS-PAS pellets, as shown in Figure 1. XRD patterns of the MS powders

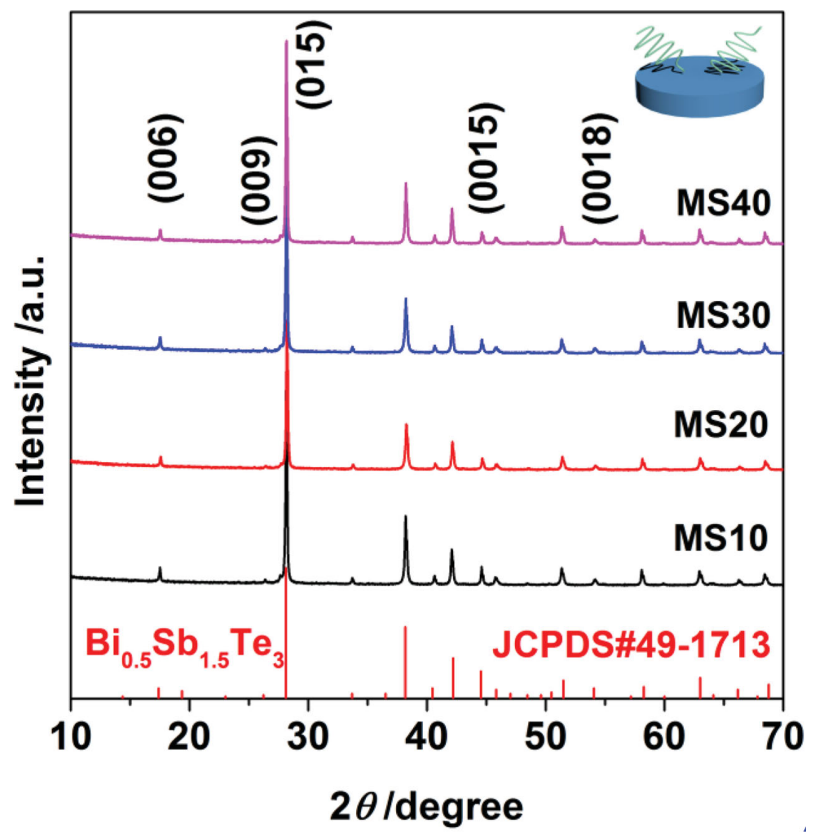

Figure 1. XRD patterns of MS-PAS bulk specimens fabricated at varying linear speed from $10-40 \mathrm{~m} \mathrm{~s}^{-1}$.

before PAS processing were also carried out and are shown in Figure S1 (Supporting Information). All patterns could be indexed to a rhombohedral $\mathrm{Bi}_{0.5} \mathrm{Sb}_{1.5} \mathrm{Te}_{3}$ single phase (JCPDS 49-1713) presented at the bottom of the figure. The orientation factors $F$ were calculated according to the following equations: ${ }^{[39]}$

$$
\begin{aligned}
& F=\frac{P-P_{0}}{1-P_{0}} \\
& P_{0}=\frac{I_{0}(00 l)}{\sum I_{0}(h k l)} \\
& P=\frac{I(00 l)}{\sum I(h k l)}
\end{aligned}
$$

where $P$ and $P_{0}$ are the ratios of the integral intensities of the (00l) planes to the intensities of the $(h k l)$ planes for preferentially and randomly orientated samples, respectively. The calculated $F$ values range from 0.02 to 0.03 , which are much lower than those produced by mechanical alloying-spark plasma sintering(MA-SPS) and hot deformation (HD) samples, ${ }^{[40]}$ and indicate the random crystalline orientations of all MS-PAS bulk specimens, which is beneficial for the fabrication of TE modules for industrial applications. Provided the $F$ value of the ZM ingots is around 1.0 along the crystal growth direction, it also suggests that the MS-PAS method can almost eliminate the intrinsic orientation of ZM ingots by crystal refinement, as was evidenced by the subsequent microstructure analysis.

To further analyze the morphological differences between the MS-PAS samples and the ZM ingots, field-emission scanning electron microscopy (FESEM) and back-scattered electron 


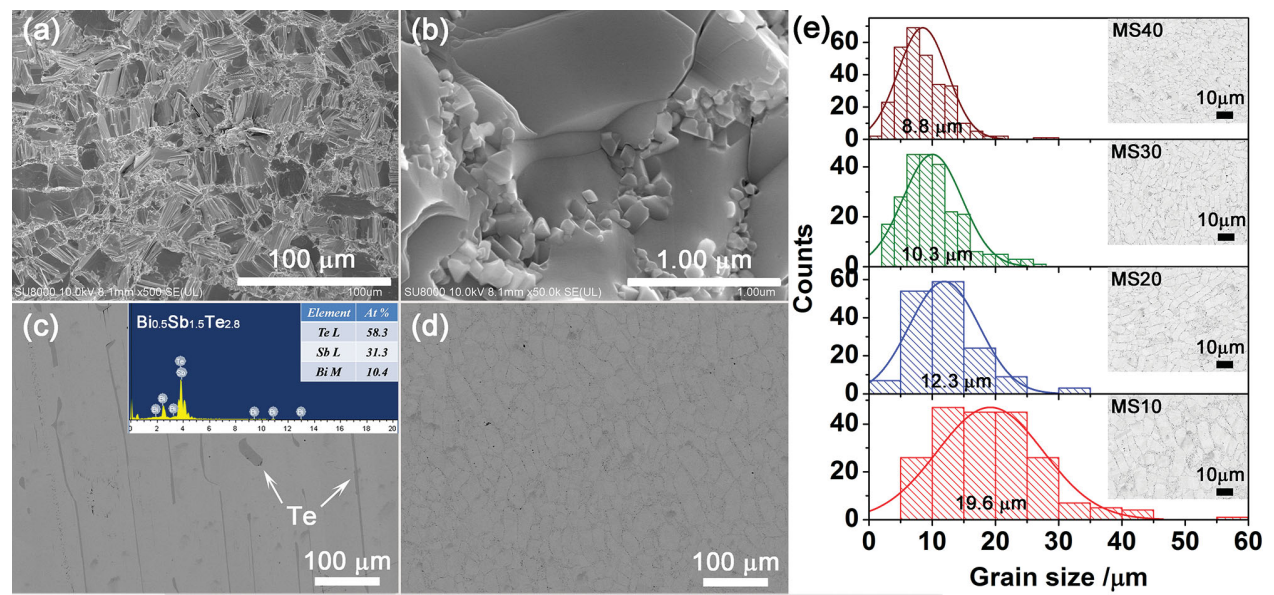

Figure 2. a) FESEM image and b) an enlarged view of the free fracture surface of the MS10 specimen, c,d) BSE images of the polished surfaces of the ZM ingot (c) and the MS10 sample (d). The inset in (c) shows the EDS results of the ZM matrix. e) Grain size distribution of MS-PAS specimens with insets showing the BSE image.

(BSE) images are presented in Figure 2. Herein, the MS10 sample was taken as a representative for comparison with ZM ingots. The FESEM image of the MS10 specimen in Figure 2a shows a random distribution of crystals without an obvious preferred orientation, which is in accordance with the extremely low orientation factor. A large number of nanoprecipitates with an average size of around $50 \mathrm{~nm}$ can be found sticking to the grain boundaries, as shown in Figure 2b. The energy dispersive spectroscopy (EDS) results in the inset of Figure 2c indicate a slight Te deficiency in the ZM matrix. Substantial Te stripes with dark contrast were found in the ZM ingots, as pointed out by the arrows, which is consistent with previous results. ${ }^{[32]}$ Such regions may act as donors to compensate for the increasing hole concentration originating from anti-structural defects by substituting Te vacancies with $\mathrm{Bi}$ or $\mathrm{Sb}$ atoms. The BSE image of the MS10 sample shows a uniform distribution of crystal grains with grain boundaries being decorated with nanostructured precipitates. The grain size distribution (of the matrix) calculated by the linear intercept method is displayed in Figure 2e. The MS10 samples show a wide distribution in grain sizes ranging from the sub-micrometer range to tens of micrometers. The crystalline sizes decrease gradually with increasing MS linear speed, which is also manifested in Figures S2 and S3 (Supporting Information).

High-resolution transmission electron microscopy (HRTEM) analysis was carried out to characterize the crystal defects that may exert a significant influence on the TE performance and the mechanical properties, as depicted in Figure 3. It is obvious from Figure 3a,b that a large dislocation loop and complicated dislocation networks occur on the $(00 l)$ cleavage planes, which may result from the ease of cleavage of the $(00 l)$ planes due to a weak van der Waals bond between the $\mathrm{Te}^{(1)}-\mathrm{Te}^{(1)}$ planes. In contrast, Figure $3 \mathrm{c}$ shows much smaller crystal sizes of around $500 \mathrm{~nm}$ for the MS10 sample, indicating a wide distribution of grain sizes in the MS-PAS samples. This kind of hierarchical structure consists of particles ranging from 50-nm nanoparticles to submicrometer grains up to $20-\mu \mathrm{m}$ lamellar structures, which may have a significant influence on the TE and mechanical properties. Twin crystals can be found in Figure 3d, where the inset corresponds to the fast Fourier transform (FFT) image of the twin crystal area. The calculated interplanar distances of this region are $0.33 \mathrm{~nm}$ and $0.53 \mathrm{~nm}$, which is consistent with the (009) and (006) planes of grain 1 and grain 2 of $\mathrm{Bi}_{0.5} \mathrm{Sb}_{1.5} \mathrm{Te}_{3}$ (JCPDS 49-1713), respectively. Additionally, as displayed in Figure 3e, a nanoparticle can be found inside the matrix with a comparable size to those shown in the FESEM images. The inverse fast Fourier transform (IFFT) image is presented in the inset, indicating the apparent crystal distortions between the matrix and the nanoprecipitate, as pointed out by the arrows. However, the EDS results reveal the compositional difference of these two regions: the nanoparticle exhibits a Sb-rich phase as opposed to the matrix, which is in good agreement with the elemental mapping results using electron-probe microanalysis (EPMA) as indicated by the dotted ovals in Figure S4 (Supporting Information).

\subsection{Thermoelectric Properties}

Table 1 lists the matrix composition and room-temperature TE transport properties of ZM and MS-PAS specimens in comparison with those from reported hot pressing (HP) and HD samples with the same composition. ${ }^{[1]}$ At least 20 points on the matrix were collected by EDS to calculate the average composition values. The results show that the matrix compositions are uniform for these two sets of samples, indicating that the MS-PAS technique can produce an extremely homogeneous matrix. The Seebeck coefficients of all MS-PAS samples were comparable to those of the ZM ingot. It should be noted that the concentration of holes is somewhat increased in the MS-PAS synthesized samples as compared to the carrier concentration in the ZM ingot (Figure S5a, Supporting Information). This is likely the result of a slight Te evaporation during the MS and PAS processing. Due to the grain refinement a reduction in carrier mobility is also found in the MS-PAS samples which leads to lower electrical conductivities that decrease further with increasing cooling rate. Assuming the dominancy of acoustic phonon scattering at room temperature, a single 

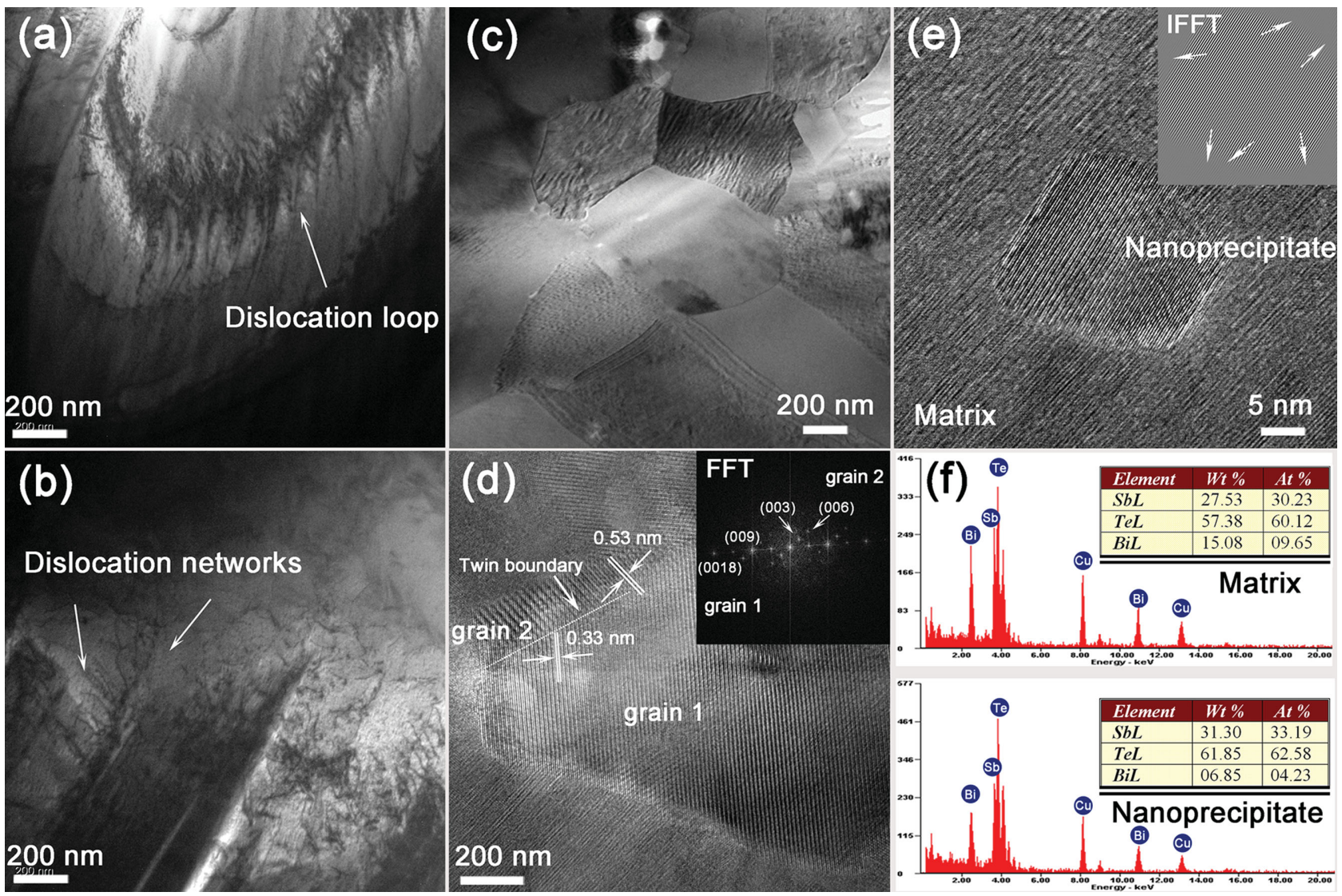

Figure 3. HRTEM images of a) ZM ingots with large dislocation loops, b) intricate dislocation networks on the cleavage plane, c,d) MS10 sample (c) with twin boundaries (d), e) a nanodot, and f) EDS results for the nanoprecipitate and the matrix of (e). The insets in (d) and (e) show the FFT and IFFT images of the corresponding twin crystals and the nanodot, respectively.

parabolic band model has often been used to calculate the carrier effective mass $\left(m^{*}\right){ }^{[42]}$ In $\mathrm{Bi}_{0.5} \mathrm{Sb}_{1.5} \mathrm{Te}_{3}$, due to the complicated scattering processes and the non-parabolic nature of the valence band, such simplified calculations may not be fully reliable. Nevertheless, such an approach generally provides a trend for the calculated effective mass $m^{*}$ of samples fabricated by various methods. ${ }^{[41]}$ The effective masses of the MS-PAS samples remained unchanged compared to those of the ZM and HP specimens, ${ }^{[41]}$ attesting to the fact that the MS-PAS technique does not alter $m^{*}$. The much larger $m^{*}$ in the HD samples ${ }^{[41]}$ may thus be attributed to the existence of a higher concentration of lattice defects, which is manifested by a dramatic decrease in the carrier mobility of the HD samples for hole concentrations comparable to those of MS-PAS fabricated compounds.

The temperature dependence of the TE properties for the ZM and MS-PAS samples is displayed in Figure 4. As documented in Figure 4a, all samples show behavioral characteristics of a

Table 1. Matrix composition, Seebeck coefficient $\alpha$, electrical conductivity $\sigma$, hole concentration $p$, carrier mobility $\mu_{\mathrm{H}}$, and effective mass $m^{*}$ of ZM ingots and MS-PAS samples measured at room temperature. For comparison, we also include data for HP and HD samples. ${ }^{[41]}$

\begin{tabular}{|c|c|c|c|c|c|c|}
\hline Sample & $\begin{array}{c}\alpha \\
{\left[\mu \vee K^{-1}\right]}\end{array}$ & $\begin{array}{c}\sigma \\
{\left[10^{4} \mathrm{~S} \mathrm{~m}^{-1}\right]}\end{array}$ & $\begin{array}{c}p \\
{\left[10^{19} \mathrm{~cm}^{-3}\right]}\end{array}$ & $\begin{array}{c}\mu \\
{\left[\mathrm{cm}^{2} \mathrm{~V}^{-1} \mathrm{~s}^{-1}\right]}\end{array}$ & $m^{*} / m_{0}$ & Matrix composition \\
\hline ZM & 218.2 & 8.29 & 1.3 & 389.6 & 0.9 & $\mathrm{Bi}_{10.2} \mathrm{Sb}_{29.8} \mathrm{Te}_{60.0}$ \\
\hline MS10 & 213.10 & 7.32 & 1.9 & 241.6 & 1.0 & $\mathrm{Bi}_{10.1} \mathrm{Sb}_{29.5} \mathrm{Te}_{60.3}$ \\
\hline MS20 & 214.2 & 6.59 & 2.0 & 204.3 & 1.1 & $\mathrm{Bi}_{10.1} \mathrm{Sb}_{29.7} \mathrm{Te}_{60.2}$ \\
\hline MS30 & 231.1 & 5.81 & 1.7 & 215.0 & 1.1 & $\mathrm{Bi}_{10.3} \mathrm{Sb}_{29.7} \mathrm{Te}_{60.0}$ \\
\hline MS40 & 226.0 & 5.86 & 1.6 & 228.5 & 1.0 & $\mathrm{Bi}_{10.2} \mathrm{Sb}_{29.5} \mathrm{Te}_{60.4}$ \\
\hline$H P^{a)}$ & 218 & 5.0 & 2.6 & 122 & 1.4 & $\mathrm{~N} / \mathrm{A}$ \\
\hline$H D^{a)}$ & 255 & 4.5 & 2.0 & 140 & 1.6 & $\mathrm{~N} / \mathrm{A}$ \\
\hline
\end{tabular}

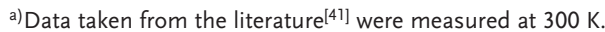


degenerate semiconductor. The electrical conductivity $\sigma$ of the MS-PAS samples decreases with increasing MS linear speed over the whole temperature range. The room-temperature Seebeck coefficients of the MS-PAS specimens were comparable to those of the ZM ingots, as shown in Figure 4b. The slightly enhanced hole concentrations in the MS-PAS samples (summarized in Table 1) help to shift the onset of intrinsic carrier excitations to higher temperatures by about $25 \mathrm{~K}$. This is reflected by the position of the Seebeck coefficient peak value. The resulting power factors of the MS-PAS samples were around $3.0 \times 10^{-3} \mathrm{~W}$ $\mathrm{m}^{-1} \mathrm{~K}^{-2}$, which is lower than that of the ZM ingot, but in line with previously reported values. ${ }^{[15]}$ The MS-PAS samples show a reduction of around $50 \%$ in the thermal conductivity over the ZM ingots. It is interesting to note that all MS-PAS specimens have an almost identical thermal conductivity $\kappa$ in the temperature range of $300-500 \mathrm{~K}$, a situation that is quite different from that of reported data. ${ }^{[43]}$ Based on the single parabolic band approximation mentioned above, the Lorenz number $L_{0}$ was determined and used to subtract the electronic contribution $\kappa_{\mathrm{e}}$ from the total thermal conductivity $\kappa$ to obtain the lattice and ambipolar thermal conductivities $\kappa_{\mathrm{L}}+\kappa_{\mathrm{amb}}$, according to the equation

$\kappa_{\mathrm{L}}+\kappa_{\mathrm{amb}}=\kappa-\kappa_{\mathrm{e}}=\kappa-L_{0} \sigma T$
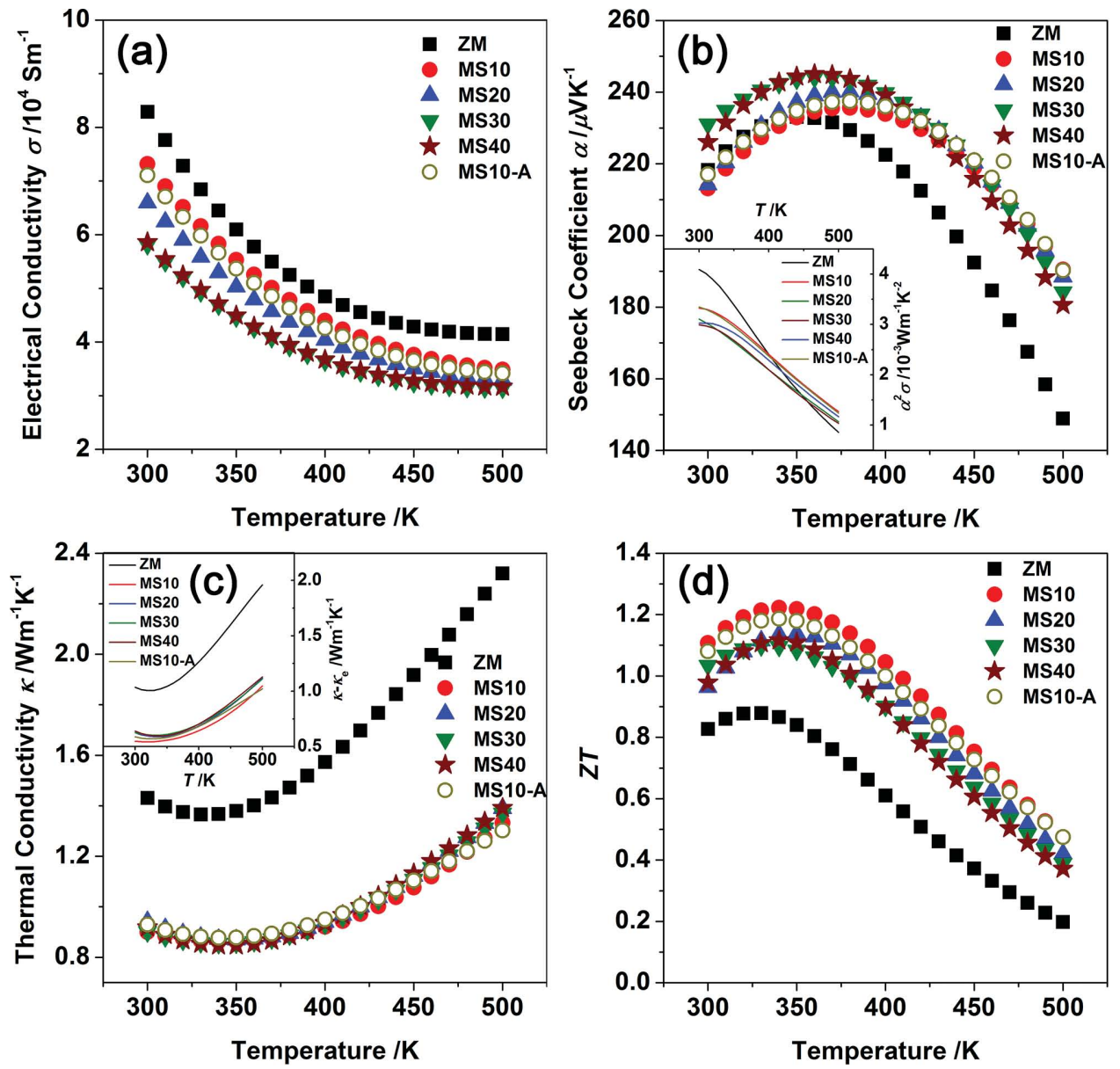

The calculated results are plotted in the inset of Figure 4c. The lowest $\kappa_{\mathrm{L}}$ of $0.55 \mathrm{~W} \mathrm{~m}^{-1} \mathrm{~K}^{-1}$ was achieved at $300 \mathrm{~K}$ for the MS10 sample, representing a reduction of about $50 \%$ compared to that of the ZM ingot. Benefitting from the significantly decreased lattice thermal conductivity, a peak $Z T$ of 1.22 was obtained at $340 \mathrm{~K}$ for the MS10 specimen, which is an enhancement of about $40 \%$ over the ZM ingot.

In order to shed light on the dramatic reduction of $\kappa_{\mathrm{L}}$ in the MS-PAS samples, we calculated the electron and phonon mean-free path at room temperature assuming the dominance of acoustic phonon scattering. The carrier mean-free path $l_{0}$ is given by ${ }^{[44]}$

$l_{0}=\frac{3 \mu\left(2 \pi m^{*} k T\right)^{\frac{1}{2}}}{4 e}$

where $m^{*}$ is the carrier effective mass, $\mu$ is the carrier mobility, $k$ is the Boltzmann constant and $e$ is the electron charge. The phonon mean free path $l_{\mathrm{ph}}$ can be estimated from the lattice thermal conductivity $\kappa_{\mathrm{L}}$ expressed as

Figure 4. Temperature dependence of a) electrical conductivity $\sigma$, b) Seebeck coefficient $\alpha$, c) thermal conductivity $\kappa$, and d) ZT for the ZM ingot, MS-PAS specimens, and MS10 annealed sample denoted by MS10-A. The insets in (b) and (c) show the power factor $\alpha^{2} \sigma$ and the combined lattice and ambipolar thermal conductivity $\kappa-\kappa_{\mathrm{e}}$ as a function of temperature. 

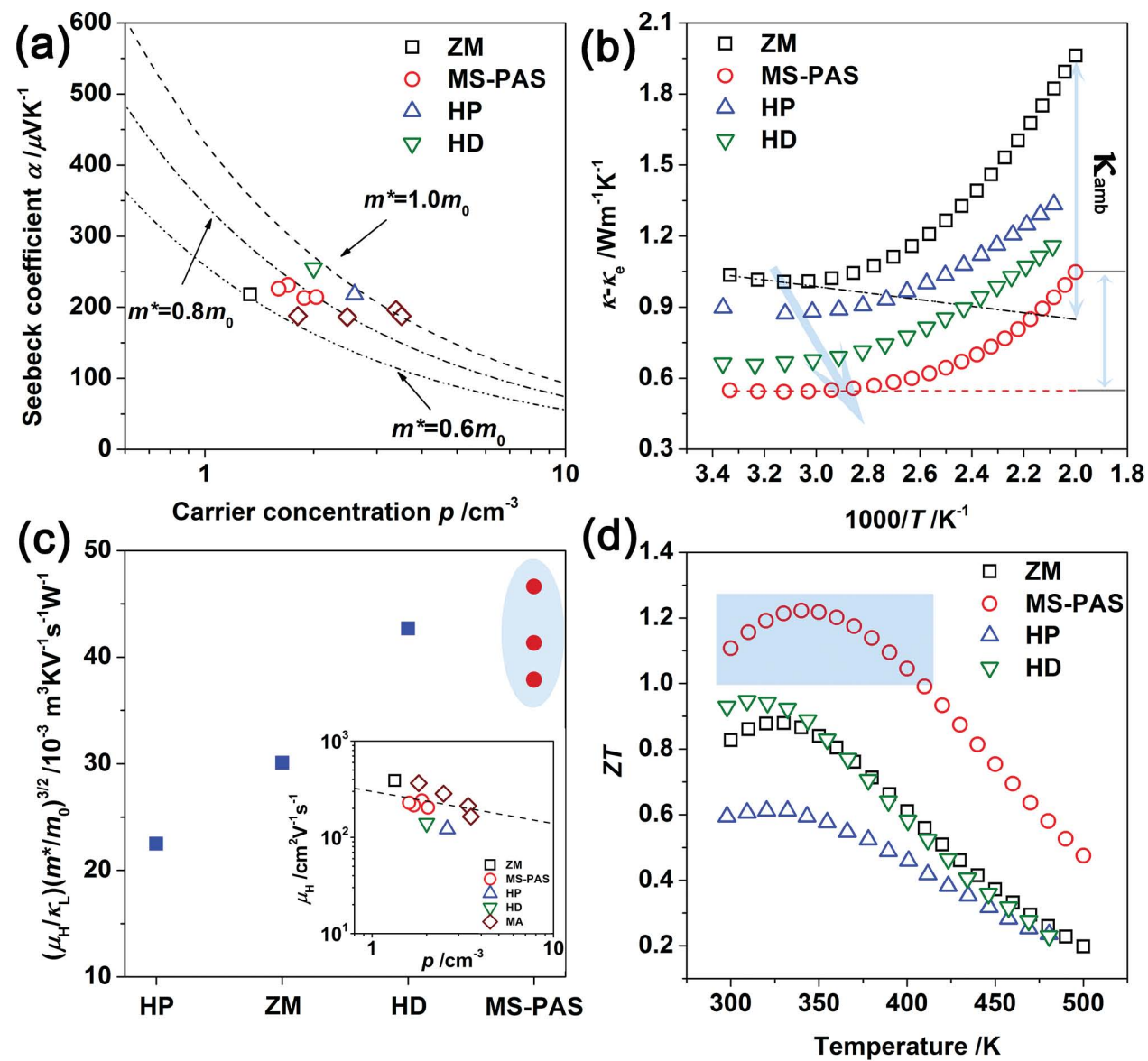

Figure 5. a) Pisarenko plot $(\alpha \sim p)$ at $300 \mathrm{~K}$, b) $\kappa-\kappa_{\mathrm{e}}$ as a function of $1000 / T$, c) calculated $\left(\mu_{\mathrm{H}} / \kappa_{\mathrm{L}}\right)\left(\mathrm{m}^{*} / m_{0}\right)^{3 / 2}$, and d) $Z T$ values of p-type $\mathrm{Bi}_{0.5} S \mathrm{~b}_{1.5} \mathrm{Te}_{3}$ fabricated by ZM, MS-PAS, HP, and HD. The inset in (c) plots the carrier mobility $\mu_{H}$ as a function of hole concentration $p$.

$\kappa_{L}=\frac{1}{3} C_{V} v l_{p h}$

where $C_{\mathrm{v}}$ is the specific heat and $v$ is the sound velocity measured by the pulse-echo method. The calculated $l_{0}$ of the ZM ingot is $26 \mathrm{~nm}$, which is much larger than the $15-18 \mathrm{~nm}$ of the MS-PAS samples. Together with the computed $l_{\mathrm{ph}}$ of the MS specimens $(6-8 \AA)$ and the ZM ingot $(12 \AA)$, it suggests that the numerous nanoparticles and interfaces generated during the MS-PAS synthesis decrease the carrier and phonon meanfree paths to a comparable degree (Figure S5b, Supporting Information).

To further clarify the differences between the $\mathrm{Bi}_{0.5} \mathrm{Sb}_{1.5} \mathrm{Te}_{3}$ samples with the same composition but prepared by different methods: ZM, MS-PAS, HP, and HD; the relevant data describing the TE performance are summarized and listed in Figure 5. The Pisarenko plot is shown in Figure 5a. It is evident that the Seebeck coefficients of the ZM and MS-PAS samples show a good consistency with those reported for the HP and HD specimens. By plotting $\kappa-\kappa_{\mathrm{e}}$ vs. $1000 / T$ in Figure $5 \mathrm{~b}$, we may conclude that the MS-PAS samples possess the lowest lattice thermal conductivity. Moreover, the ambipolar thermal conductivity $\kappa_{\mathrm{amb}}$ in the HP, HD, and MS-PAS specimens do not rise as steeply as that in the ZM ingot as indicated by the arrow in Figure $5 \mathrm{~b}$. Additionally, the calculated term $\left(\mu_{\mathrm{H}} / \kappa_{\mathrm{L}}\right)$ $\left(m^{*} / m_{0}\right)^{3 / 2}$, which is proportional to the TE efficiency, ${ }^{[45]}$ is depicted in Figure $5 c$. The MS-PAS samples show comparable values to that of the HD specimen of the same composition. ${ }^{41]}$ The inset in Figure $5 \mathrm{c}$ shows carrier mobilities $\mu_{\mathrm{H}}$ that roughly follow the relationship $\mu_{\mathrm{H}} \propto p^{-1 / 3}$ at room temperature, which is characteristic of the conduction in a degenerate semiconductor. ${ }^{[46]}$ The temperature dependence of the $Z T$ values for these samples is shown in Figure $5 d$, where we have highlighted the range where $Z T>1$. The results indicate a superior performance of the MS-PAS synthesized samples compared to the HD, HP, and ZM samples. An important issue pertains to the long-term thermal stability and reliability of the TE materials. It is well known that materials prepared by unconventional methods may be thermally unstable at elevated temperature because of the presence of large amounts of nanoprecipitates and crystal defects, such as dislocations, stacking faults and anti-site defects. ${ }^{[39,40]}$ Accordingly, to further investigate the stability of our MS10 sample with its hierarchical structure and in-situ nanoprecipitates, we annealed it at $200{ }^{\circ} \mathrm{C}$ for a week and re-measured the thermoelectric and mechanical properties. The TE performance was perfectly reproducible as shown in Figure 4, and the microstructure remained unchanged (Figure S8, Supporting Information), indicating the excellent thermal stability of our hierarchical samples. 
Table 2. Mean grain size, density, and elastic properties measured at room temperature in comparison to ZM and HP samples. ${ }^{[47]}$

\begin{tabular}{|c|c|c|c|c|c|c|c|c|}
\hline Sample & $\begin{array}{c}\text { Mean grain size } \\
{[\mu \mathrm{m}]}\end{array}$ & $\begin{array}{c}d \\
{\left[\mathrm{~g} \mathrm{~cm}^{-3}\right]}\end{array}$ & $\begin{array}{c}C_{11} \\
{[G p a]}\end{array}$ & $\begin{array}{c}G \\
{[\mathrm{GPa}]}\end{array}$ & $\begin{array}{c}E \\
{[\mathrm{GPa}]}\end{array}$ & $\begin{array}{c}B \\
{[\mathrm{GPa}]}\end{array}$ & $v$ & $G / B$ \\
\hline $\mathrm{ZM} \|$ & $\mathrm{N} / \mathrm{A}$ & 6.81 & 70 & 24 & 59 & 38 & 0.24 & 0.63 \\
\hline $\mathrm{ZM} \perp$ & $\mathrm{N} / \mathrm{A}$ & 6.81 & 74 & 16 & 44 & 53 & 0.36 & 0.30 \\
\hline MS10 & $19.6 \pm 3.2$ & 6.81 & 57 & 20 & 50 & 29 & 0.22 & 0.69 \\
\hline MS20 & $12.3 \pm 2.8$ & 6.80 & 66 & 20 & 52 & 39 & 0.28 & 0.52 \\
\hline MS30 & $10.3 \pm 1.9$ & 6.80 & 53 & 20 & 48 & 26 & 0.19 & 0.77 \\
\hline MS40 & $8.8 \pm 1.8$ & 6.80 & 66 & 20 & 51 & 39 & 0.28 & 0.51 \\
\hline$H P^{a)}$ & $\mathrm{N} / \mathrm{A}$ & 6.57 & 53 & 16 & 42 & 31 & 0.28 & 0.52 \\
\hline
\end{tabular}

a) Hot pressed at $450{ }^{\circ} \mathrm{C}, 35 \mathrm{MPa}$, for $20 \mathrm{~min}$.

\subsection{Elastic Moduli and Mechanical Properties}

The average grain sizes, densities, and elastic moduli of our samples are listed in Table 2. The mean crystal size decreased with increasing MS linear speed, which is confirmed by the EPMA and FESEM results (Figures S2 and S3, Supporting Information). The sound velocities of the samples cut parallel $(\|)$ and perpendicular $(\perp)$ to the zone melting or sintering pressure direction were also measured. Due to the preferential orientation of $\mathrm{ZM}$ ingots, the velocities of the $\mathrm{ZM}_{\|}$and $\mathrm{ZM}_{\perp}$ samples were quite different, leading to anisotropic moduli. The MS-PAS samples show almost identical velocities along the two directions, indicating a random crystal orientation, which is in consistence with the XRD and FESEM results. For simplicity, only the values for the MS-PAS samples cut perpendicular to the sintering pressure direction are listed in Table 2. In comparison with the $\mathrm{HP}^{[47]}$ and $\mathrm{ZM}$ samples the MS-PAS specimens present similar elastic properties. However, the elastic moduli ( $G$ and $E$ ) of all MS-PAS samples appeared to be slightly reduced compared to those of the $\mathrm{ZM}_{\|}$ ingots, whereas an increase of $10-20 \%$ was found for the perpendicular MS-PAS samples as compared to the $\mathrm{ZM}_{\perp}$ samples. The calculated Poisson's ratio of all these specimens ranged from 0.19 to 0.36 and, together with the distribution of $G / B$ in the range of $0.30-0.77$, this indicates a mixture of covalent and ionic bonds in the p-type $\mathrm{Bi}_{0.5} \mathrm{Sb}_{1.5} \mathrm{Te}_{3}$ alloys synthesized by these fabrication methods. ${ }^{[48]}$ Similar results were found in filled antimonide skutterudites. ${ }^{[25]}$

Figure 6 shows the Vickers hardness, fracture toughness, and grain sizes of samples prepared by the ZM and MS-PAS methods. The MS-PAS samples exhibit an almost identical $\mathrm{Hv}$ of $0.4 \mathrm{GPa}$, some $50 \%$ improvement over the $0.26 \mathrm{GPa}$ of the $\mathrm{ZM}$ ingot, which can mainly be ascribed to the grain refinement and random distribution of crystallites resulting from the MS-PAS technique. However, the $H v$ within the series of MS-PAS samples shows a weak dependence on the grain size. The remarkable increase in $H v$ of the MS samples contributes to the enhanced machinability, which is beneficial for the manufacturing process of TE devices. The fracture toughness $K_{\text {IC }}$ of the MS-PAS specimens exhibits an enhancement of about $26-40 \%$ over that of the ZM ingot, and increases linearly as the grain size becomes smaller. Three factors may be responsible for the strengthening mechanism: a) the grain size reduction as described by the Hall-Petch relation, ${ }^{[49]}$ b) the hierarchical structure, ${ }^{[50]}$ c) the random crystal orientation. Furthermore, the optical images of micro bricks (dimension $1.6 \mathrm{~mm} \times$ $1.4 \mathrm{~mm} \times 1.4 \mathrm{~mm}$ ) cut from the ZM ingots and MS10 samples are shown in Figure S7 (Supporting Information) and indicate that the ZM ingots suffer from obvious machining defects in the manufacturing process, such as delamination, pitting, edge chipping, and surface cracks, thus leading to an extremely low productivity and mechanical instability.
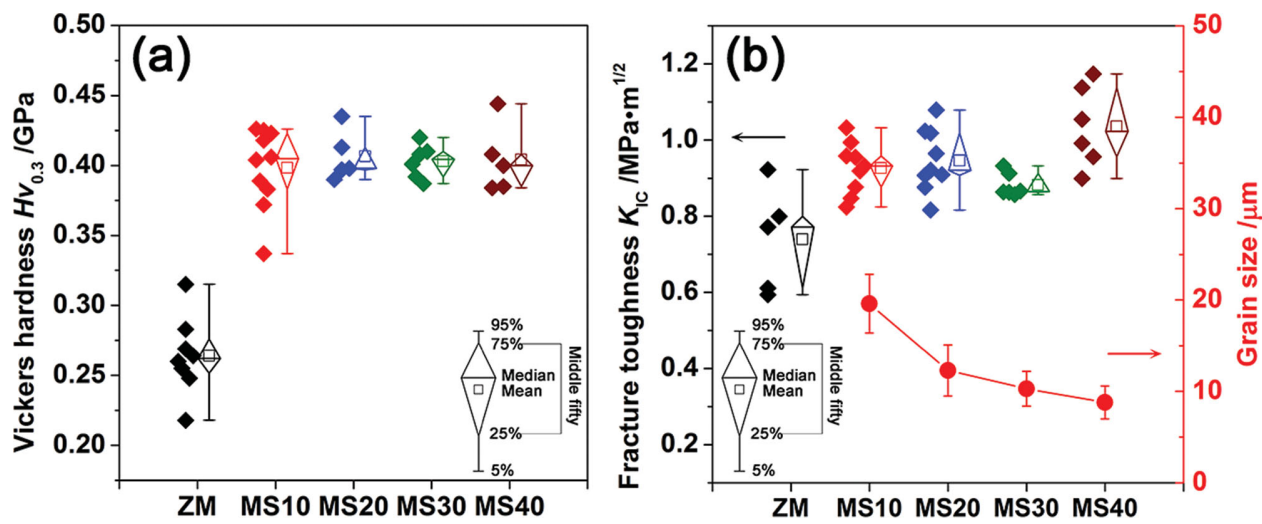

Figure 6. Statistical box charts of a) Vickers hardness $H v$ and b) fracture toughness $K_{\mathrm{IC}}$ together with raw data of ZM and MS-PAS samples measured at room temperature. The grain size is plotted as a function of the MS cooling rate. 

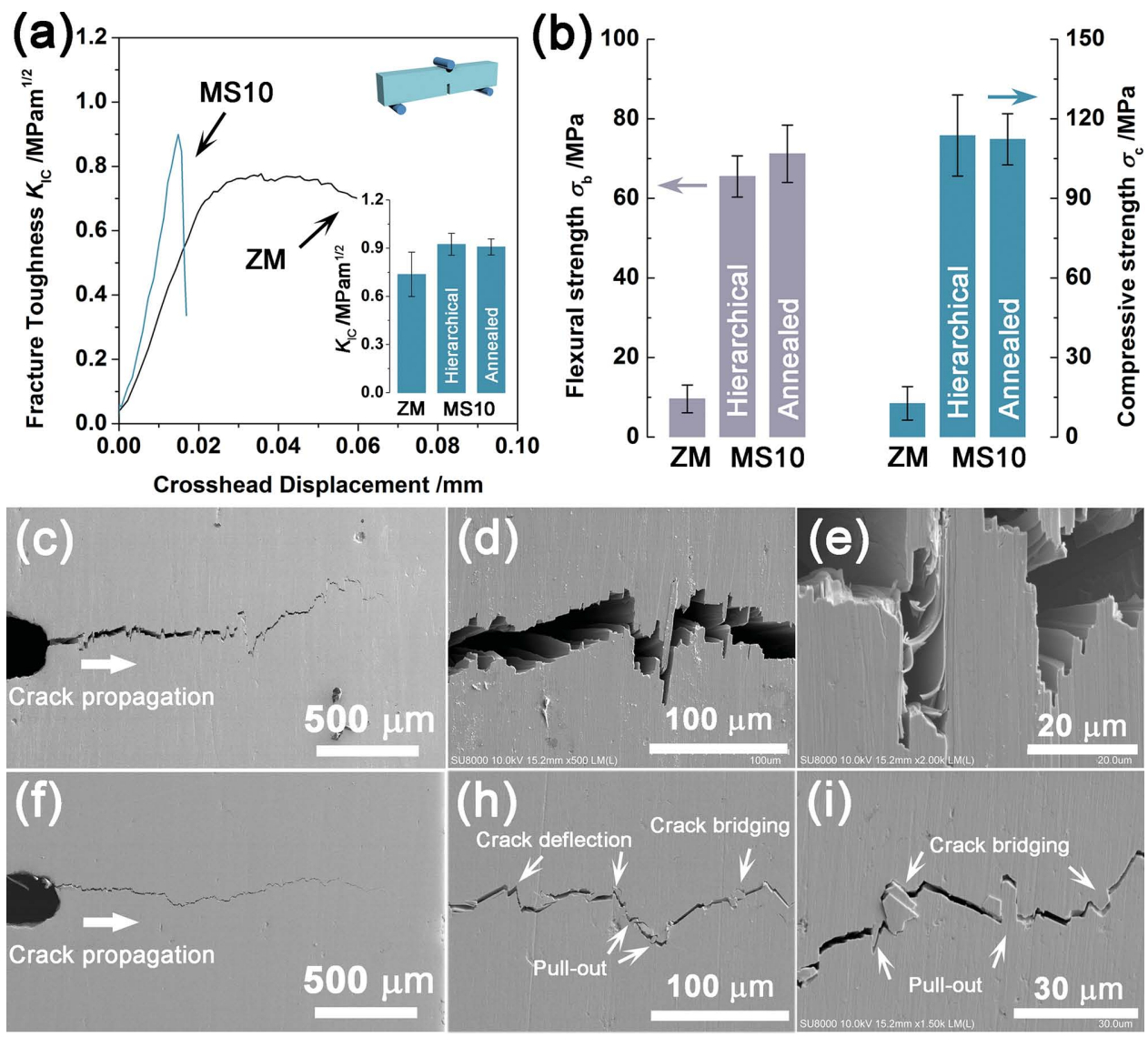

Figure 7. a) Fracture toughness-displacement curves of ZM and MS10 samples with the inset showing the $K_{\mathrm{IC}}$ values of ZM, MS10, and MS10 annealed samples. b) Room-temperature flexural and compressive strengths of hierarchical and annealed specimens (MS10) in comparison to ZM ingots. c-i) Crack propagation and fracture surfaces of the ZM ingot (c-e) and the MS10 sample (f-i).

Figure 7a displays the fracture toughness-displacement curves of ZM and MS10 samples. The ZM samples present a stable fracture: ${ }^{[51]}$ the crack may be arrested by the plastic zone ahead of the crack tip due to the ease of cleavage along the crystal growth direction. Then the peak load extends gradually, reaching a plateau, and subsequently decreases slowly. In contrast, the MS10 samples exhibit an unstable fracture, that is, the complete failure happens at the peak load with an immediate drop in the loading force. ${ }^{[51]}$ The fracture surface of the ZM sample, shown in Figure 7c-e, demonstrates a rupture of $\mathrm{Bi}_{0.5} \mathrm{Sb}_{1.5} \mathrm{Te}_{3}$ layers oriented perpendicular to the direction of the propagating crack, in other words, breaking the strong covalent and ionic bonds. The easy cleavage nature (van der Waals bonding) of the $\mathrm{Te}^{(1)}-\mathrm{Te}^{(1)}$ layers is responsible for the crack deflection. Taking the MS10 sample as a representative case its fracture image is shown in Figure $7 \mathrm{f}-\mathrm{i}$. The grain refinement and hierarchical structures resulting from MS-PAS processing contribute to the obvious crack deflection, crack bridging, and pull-out of long grains as indicated by the white arrows, dissipating more energy during the crack propagation. ${ }^{[40,51,52]}$ In addition, a broad distribution of nanoparticles at the grain boundaries can also impede crack propagation. ${ }^{[53]}$ These toughening mechanisms may account for the enhanced fracture toughness of the MS10 samples, as shown in the inset of Figure 7a. The room temperature flexural and compressive strength values of the ZM, MS10, and MS10-A samples are displayed in Figure 7b. The MS10 samples exhibit an increase of about six fold and eightfold in flexural strength and compressive strength, respectively, over the ZM ingots, which is related to the presence of hierarchical structures and in-situ nanoprecipitates. It should be noted that all the annealed samples exhibit an almost identical or slight enhancement in mechanical strength and lattice thermal conductivity as compared to their nonannealed counterparts, which may be ascribed to the relief of thermal stresses during the annealing process. In conclusion, the hierarchical nanostructured alloys fabricated by the MS-PAS technique display superior mechanical properties and excellent thermal stability up to $200^{\circ} \mathrm{C}$, demonstrating great potential in practical applications, especially in the area of microdevices.

The flexural and compressive strengths of the $\mathrm{ZM}$ and MS-PAS specimens measured at 25,100 , and $200{ }^{\circ} \mathrm{C}$ are shown in Figure 8. The original data fitted by a Weibull distribution are displayed in Tables S1 and S2 (Supporting Information). As shown in Figure 8a,b all MS-PAS samples exhibit an increase of about six fold and eight- to tenfold in the flexural and compressive strengths, respectively, compared to those of the ZM specimens. The tiny enhancement in the flexural strength $\sigma_{\mathrm{b}}$ and the compressive strength $\sigma_{\mathrm{c}}$ with increasing MS linear speed may also result from the grain refinement as explained by the Hall-Petch relation ${ }^{[49,54]}$ 

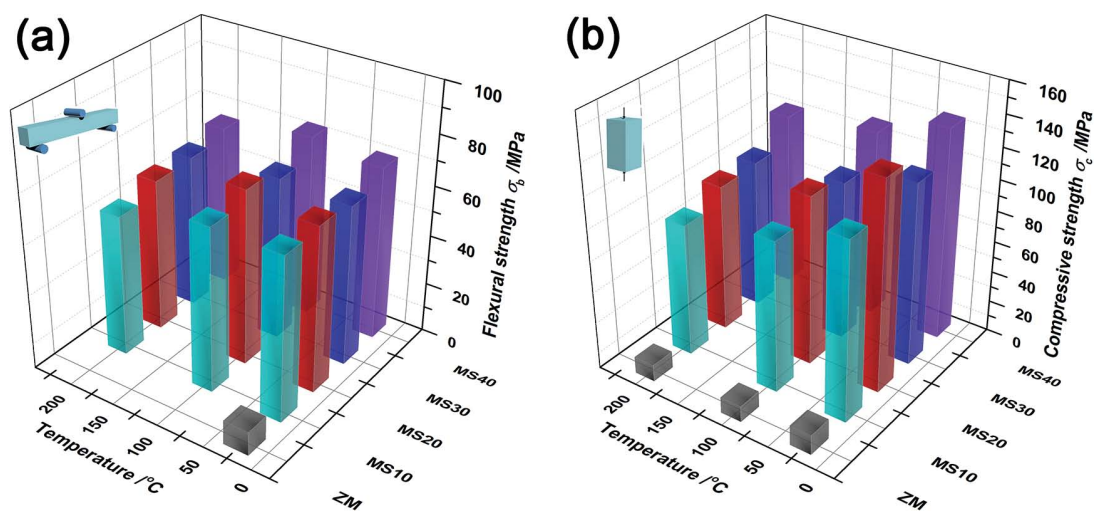

Figure 8. a) The flexural strength $\sigma_{\mathrm{b}}$ and b) compressive strength $\sigma_{\mathrm{c}}$ of ZM and MS-PAS samples measured at 25,100 , and $200^{\circ} \mathrm{C}$.

$$
\sigma=\sigma_{0}+k a^{-1 / 2}
$$

where $\sigma$ and $\sigma_{0}$ are the strength of the polycrystals and corresponding single crystals, respectively, $k$ is a constant, and $a$ is the grain size. The fracture processes of the ZM and MS10 specimens were observed with a high speed video camera as shown in Figure S6 (Supporting Information). In addition, the $\sigma_{\mathrm{b}}$ and $\sigma_{\mathrm{c}}$ of the MS-PAS specimens decreased slightly with increasing temperature. At $200{ }^{\circ} \mathrm{C}$, the reduction in $\sigma_{\mathrm{c}}$ reaches a maximum of $36 \%$ for the MS20 sample. Combined with the results from microstructural analysis it can be concluded that the thermal expansion anisotropy (TEA) at high temperatures, due to the random grain orientation and almost twofold discrepancy of thermal expansion along the $a$ - and $c$-axes, ${ }^{[55]}$ of the MS-PAS samples may spontaneously increase the concentration of microcracks, ${ }^{[4,56]}$ thus resulting in a degradation in $\sigma_{\mathrm{c}}$. In order to simulate the actual working conditions of TE devices, further investigations will be performed on the reliability and fatigue behavior of MS-PAS samples under thermal and mechanical cycling.

\section{Conclusions}

In this work, both the TE performance and mechanical properties were systematically investigated for samples fabricated by the MS-PAS method that possess hierarchical structures. Owing to a significant reduction in the lattice thermal conductivity associated with a wide range of hierarchical structures, a maximum $Z T$ of 1.22 was achieved for the MS-PAS samples, which is comparable to samples prepared by HD and MA-SPS methods. Furthermore, accompanied simultaneously by a superior machinability, better mechanical properties, and excellent thermal stability, the melt-spinning-based synthesis approach of the MS-PAS samples offers great potential for commercial applications.

\section{Experimental Section}

The p-type $\mathrm{Bi}_{0.5} \mathrm{Sb}_{1.5} \mathrm{Te}_{3}$ commercially available zone-melted (ZM) ingots (Thermonamic Electronics Corporation) were crushed into powders and then cold pressed into pellets under $10 \mathrm{MPa}$. The obtained pellets were placed in a quartz tube with a $0.5 \mathrm{~mm}$ diameter nozzle, which was then placed in an RF copper coil ready for the melt-spinning process. argon gas $(0.05 \mathrm{MPa})$ was filled into the chamber to protect the ingots from oxidation in the molten state. The ingots were completely melted within $15 \mathrm{~s}$ by the induction melting as the melting point of BiSbTe alloys is relatively low (around $860 \mathrm{~K}$ ). The molten alloy was then continuously ejected onto the rotating copper roller under an argon atmosphere with a pressure of $0.04 \mathrm{MPa}$ in $20 \mathrm{~s}$. The linear speed of the copper roller varied from $10-40 \mathrm{~m} \mathrm{~s}^{-1}$. The obtained MS ribbons were handground into fine powders, which were loaded into a $20-\mathrm{mm}$ diameter graphite die and then vacuum sintered at $723 \mathrm{~K}$ under $40 \mathrm{MPa}$ for $5 \mathrm{~min}$ by the plasma-activated sintering (PAS) technique. The sintering profile and flow chart of the MS-PAS process can be found in Figure S9 and S10 (Supporting Information), respectively. In the PAS process, the activation by the force of plasma discharge before sintering is beneficial to the powders, as it can remove the impurities on the particle surface and then cause a micro-electrical discharge to activate the particle surface. Thus this method ensures a rapid sintering at lower temperatures than conventional sintering methods and suppresses the crystal growth. All sintered pellets with a size of $20 \mathrm{~mm} \times 15 \mathrm{~mm}$ showed densities that were identical to that of the ZM ingots. For simplicity, the samples prepared by the MS-PAS technique are denoted as MSx, where $x$ stands for the linear speed $\left(10-40 \mathrm{~m} \mathrm{~s}^{-1}\right)$.

The phase composition of the samples was determined by powder $X$-ray diffraction (XRD, PRO-PANalytical Empyrean, Netherlands), the diffractometer was operated at $40 \mathrm{kV}$ and $40 \mathrm{~mA}$. Microstructures of the bulk samples were investigated by electron-probe microanalysis (EPMA, JXA-8230, JEOL, Japan), field-emission scanning electron microscopy (FESEM, Hitachi SU-8020, Japan), and high-resolution transmission electron microscopy (HRTEM, JEM-2100F, JEOL, Japan), also equipped with an energy-dispersive spectroscope to determine the actual composition. Back-scattered electron (BSE) images of carefully polished surfaces of MS-PAS and ZM specimens were acquired by EPMA. The linear intercept method was adopted to determine the mean grain sizes. To guarantee the accuracy of the obtained data, a total number of about 200 intercepts was selected on each specimen to calculate the average value.

The electrical conductivity $(\sigma)$ and the Seebeck coefficient $(\alpha)$ were measured simultaneously by a standard four-probe method in the range of 300-500 K using an Ulvac-Riko ZEM-3 system. The low-temperature Hall coefficients $\left(R_{\mathrm{H}}\right)$ and low-temperature electrical conductivities $(\sigma)$ were characterized by a physical properties measurements system (PPMS-9, Quantum Design, USA) in the range of 10-300 K. The carrier concentration $(p)$ and the Hall mobility $\left(\mu_{\mathrm{H}}\right)$ were determined by

$p=1 / e R_{\mathrm{H}}$

and

$\mu_{\mathrm{H}}=\sigma R_{\mathrm{H}}$

Finally, the total thermal conductivity was calculated from $\kappa=D C_{p} d$, where $D$ is the thermal diffusivity obtained by the laser flash method (LFA-457, Netzsch, German), $C_{p}$ is the specific heat measured by a differential scanning calorimeter (DSC Q20, TA Instrument, USA), and $d$ is the density measured by the Archimedes method.

All sintered bulk specimens were cut and carefully polished to $0.5 \mu \mathrm{m}$ before mechanical testing, aiming to reduce the surface flaws, such as 
pitting and machining damage. The elastic moduli were evaluated from the measured sound velocity by using: ${ }^{[49,57]}$

$$
\begin{aligned}
& C_{11}=d v_{l}^{2} \\
& G=d v_{t}^{2} \\
& E=d \frac{3 v_{t}^{2} v_{I}^{2}-4 v_{t}^{4}}{v_{l}^{2}-v_{t}^{2}} \\
& v=\frac{E}{2 G}-1 \\
& B=\frac{E}{3(1-2 v)}
\end{aligned}
$$

where $d$ is the bulk density, $v_{l}$ and $v_{\mathrm{t}}$ are the longitudinal and transverse velocities measured by the pulse-echo method, $C_{11}$ is the longitudinal modulus, $G$ is the shear modulus, $E$ is the Young's modulus, $B$ is the bulk modulus, and $v$ is the Poisson's ratio. The Vickers hardness $(\mathrm{Hv})$ test was conducted at room temperature with an indentation force of $2.94 \mathrm{~N}$ maintained for $15 \mathrm{~s}$ on a hardness tester (430SVD, Wolpert Group, China). By measuring the diagonal length, the $H v$ values could be acquired from ${ }^{[49]}$

$$
H \nu=\frac{1.8544 F_{0}}{(2 a)^{2}}
$$

where $F_{0}$ is the applied load and $2 a$ is the average diagonal length of the indentation impression. Measurements of the fracture toughness were based on the single-edge notched beam (SENB) method. SENB samples with dimensions of $3 \mathrm{~mm} \times 2 \mathrm{~mm} \times 15 \mathrm{~mm}$ and a pre-crack size of $0.3 \mathrm{~mm} \times 1.2 \mathrm{~mm}$ were carefully cut and polished for the test, which was conducted at room temperature with a crosshead speed of $0.05 \mathrm{~mm} \mathrm{~min}^{-1}$ on a MTS universal test machine (E44.104, MTS, China). The $K_{\mathrm{IC}}$ can be derived from the following equations by recording the maximum fracture force $(F):{ }^{[58]}$

$$
\begin{aligned}
K_{I C}= & \frac{F S}{B W^{\frac{3}{2}}} f\left(\frac{c}{W}\right) \\
f\left(\frac{c}{W}\right) & =2.9\left(\frac{c}{W}\right)^{\frac{1}{2}}-4.6\left(\frac{c}{W}\right)^{\frac{3}{2}}+21.8\left(\frac{c}{W}\right)^{\frac{5}{2}} \\
& -37.6\left(\frac{c}{W}\right)^{\frac{7}{2}}+38.7\left(\frac{c}{W}\right)^{\frac{9}{2}}
\end{aligned}
$$

where $F, S, B, W, C$ are the breaking load, a supporting span of the fixture $(12 \mathrm{~mm})$, and the sample's height, width, and pre-crack length, respectively. $f(c / W)$ is the stress-intensity shape factor. As noted by Salvador et al. the cross section of TE legs in modules usually varies from $1 \mathrm{~mm} \times 1 \mathrm{~mm}$ to $4 \mathrm{~mm} \times 4 \mathrm{~mm} \cdot{ }^{[3]]}$ Consequently, the sizes of prismatic bars for 3-point bending and compressive tests in this study were chosen to be $15 \mathrm{~mm} \times 2 \mathrm{~mm} \times 2 \mathrm{~mm}$ (the bend span was fixed at $12 \mathrm{~mm}$ ) and $6 \mathrm{~mm} \times 3 \mathrm{~mm} \times 3 \mathrm{~mm}$, respectively. The flexural and compressive tests were carried out at room temperature, $100{ }^{\circ} \mathrm{C}$, and $200{ }^{\circ} \mathrm{C}$ on the same MTS machine. The bending equation can be expressed as ${ }^{[49]}$

$$
\sigma_{b}=\frac{3 P L}{2 b h^{2}}
$$

where $P$ is the fracture force, $L$ is the length of the support span $(12 \mathrm{~mm}$ fixed), and $b$ and $h$ are the specimen cross sections $(2 \mathrm{~mm} \times 2 \mathrm{~mm}$ nominal). 15 samples were prepared for each set of tests and the hightemperature strengths were evaluated by placing the samples on the fixture in a furnace purged with Ar. The samples were soaked at a specific temperature (i.e., 100 or $200^{\circ} \mathrm{C}$ ) for $10 \mathrm{~min}$ before testing to guarantee temperature homogeneity. A two-parameter Weibull distribution, suitable for characterizing the strength distribution, was employed to fit the data by using maximum likelihood estimations, of which $95 \%$ confidence estimates were determined. ${ }^{[49]}$ Moreover, a high-speed video camera (I-speed 3, Olympus, Japan) was equipped with a $10000 \mathrm{fps}$ shooting rate to record the crack propagation during the mechanical tests, facilitating the direct observation of the fracture process.

To study the thermal stability of the MS-PAS samples heat-treatment experiments were conducted on hierarchical nanostructured MS10 samples, which were sealed in vacuum $\left(10^{-4}\right.$ Torr $)$ and then annealed in a horizontal furnace (RSR 70/500/11/C 250, Nabertherm, Germany) at $200{ }^{\circ} \mathrm{C}$ for a week. This temperature corresponds to the highest service temperature of $\mathrm{Bi}_{2} \mathrm{Te}_{3}$-based modules. The microstructures, thermoelectric performance, and mechanical properties of the annealed samples were investigated in comparison to that of the specimens before annealing.

\section{Supporting Information}

Supporting Information is available from the Wiley Online Library or from the author.

\section{Acknowledgements}

The authors thank Rong Jiang and Tingting Luo for help with the HRTEM analysis. This work is financially supported by the National Basic Research Program of China (973 program) under project 2013CB632502, the International Science \& Technology Cooperation Program of China (Grant No. 2011DFB60150), the Natural Science Foundation of China (Grant No. 51402222, 51172174) and the 111 Project of China (Grant No. B07040).

Received: August 12, 2014

Revised: October 10, 2014

Published online: November 14, 2014

[1] T. C. Harman, P. J. Taylor, M. P. Walsh, B. E. LaForge, Science 2002, 297, 2229.

[2] M. S. Dresselhaus, G. Chen, M. Y. Tang, R. G. Yang, H. Lee, D. Z. Wang, Z. F. Ren, J. P. Fleurial, P. Gogna, Adv. Mater. 2007, 19, 1043.

[3] D. M. Rowe, CRC Handbook of Thermoelectrics, CRC Press, Boca Raton, FL, USA 1995.

[4] G. J. Snyder, E. S. Toberer, Nat. Mater. 2008, 7, 105.

[5] T. M. Tritt, M. A. Subramanian, MRS Bull. 2006, 31, 188.

[6] K. Koumoto, T. Mori, Thermoelectric Nanomaterials, Springer, Heidelberg, Germany 2013.

[7] B. Poudel, Q. Hao, Y. Ma, Y. Lan, A. Minnich, B. Yu, X. Yan, D. Wang, A. Muto, D. Vashaee, X. Chen, J. Liu, M. S. Dresselhaus, G. Chen, Z. Ren, Science 2008, 320, 634.

[8] H. J. Goldsmid, Electronic Refrigeration, Pion, London, UK 1986

[9] G. Kavei, M. Karami, Bull. Mater. Sci. 2006, 29, 659.

[10] a) J. Sun, B. Bhushan, RSC Adv. 2012, 2, 7617; b) T. Tan, N. Rahbar, S. M. Allameh, S. Kwofie, D. Dissmore, K. Ghavami, W. O. Soboyejo, Acta Biomater. 2011, 7, 3796; c) R. Lakes, Nature 1993, 361, 511.

[11] a) M. K. Habibi, S. P. Joshi, M. Gupta, Acta Mater. 2010, 58, 6104; b) A. R. Studart, Adv. Mater. 2012, 24, 5024; c) G. Liu, G. Zhang, 
F. Jiang, X. Ding, Y. Sun, J. Sun, E. Ma, Nat. Mater. 2013, 12, 344; d) H. D. Espinosa, T. Filleter, M. Naraghi, Adv. Mater. 2012, 24, 2805.

[12] K. Biswas, J. He, I. D. Blum, C. I. Wu, T. P. Hogan, D. N. Seidman, V. P. Dravid, M. G. Kanatzidis, Nature 2012, 489, 414.

[13] L. D. Zhao, S. Hao, S. H. Lo, C. I. Wu, X. Zhou, Y. Lee, H. Li, K. Biswas, T. P. Hogan, C. Uher, C. Wolverton, V. P. Dravid, M. G. Kanatzidis, J. Am. Chem. Soc. 2013, 135, 7364.

[14] a) J. Y. Rho, L. K. Spearing, P. Zioupos, Med. Eng. Phys. 1998, 20, 92; b) F. Barthelat, H. Tang, P. Zavattieri, C. M. Li, H. Espinosa, J. Mech. Phys. Solids 2007, 55, 306; c) M. Launey, E. Munch, D. Alsem, H. Barth, E. Saiz, A. Tomsia, R. Ritchie, Acta Mater. 2009, 57, 2919; d) F. Bouville, E. Maire, S. Meille, B. Van de Moortèle, A. J. Stevenson, S. Deville, Nat. Mater. 2014, 13, 508.

[15] W. Xie, X. Tang, Y. Yan, Q. Zhang, T. M. Tritt, Appl. Phys. Lett. 2009, $94,102111$.

[16] D. Qi, X. Tang, H. Li, Y. Yan, Q. Zhang, J. Electron. Mater. 2010, 39, 1159.

[17] a) B. Du, H. Li, J. Xu, X. Tang, C. Uher, Chem. Mater. 2010, 22, 5521; b) W. Luo, H. Li, Y. Yan, Z. Lin, X. Tang, Q. Zhang, C. Uher, Intermetallics 2011, 19, 404; c) H. Li, X. Tang, X. Su, Q. Zhang, Appl. Phys. Lett. 2008, 92, 202114; d) X. Zhang, H. Liu, Q. Lu, J. Zhang, F. Zhang, Appl. Phys. Lett. 2013, 103, 063901; e) W. Xie, D. A. Hitchcock, H. J. Kang, J. He, X. Tang, M. Laver, B. Hammouda, Appl. Phys. Lett. 2012, 101, 113902; f) W. Xie, S. Wang, S. Zhu, J. He, X. Tang, Q. Zhang, T. Tritt, J. Mater. Sci. 2013, 48, 2745; g) A. A. Melnikov, V. G. Kostishin, S. A. Kichik, V. V. Alenkov, J. Nano-Electron. Phys. 2014, 6, 03061.

[18] J. R. Salvador, R. A. Waldo, C. A. Wong, M. Tessema, D. N. Brown, D. J. Miller, H. Wang, A. A. Wereszczak, W. Cai, Mater. Sci. Eng. B 2013, 178, 1087.

[19] L. D. Ivanova, L. I. Petrova, Y. V. Granatkina, V. G. Leontyev, A. S. Ivanov, S. A. Varlamov, Y. P. Prilepo, A. M. Sychev, A. G. Chuiko, I. V. Bashkov, Inorg. Mater. 2013, 49, 120.

[20] H. H. Liebermann, Rapidly solidified alloys: processes, structures, properties, applications, Marcel Dekker, New York, NJ, USA 1993.

[21] P. Delhaes, Fibers and Composites, CRC Press, Boca Raton, FL, USA 2003.

[22] A. Ziabicki, Fundamentals of fibre formation: the science of fibre spinning and drawing, Wiley, London, UK 1976.

[23] R. H. Baughman, A. A. Zakhidov, W. A. de Heer, Science 2002, 297, 787.

[24] a) V. Ravi, S. Firdosy, T. Caillat, B. Lerch, A. Calamino, R. Pawlik, M. Nathal, A. Sechrist, J. Buchhalter, S. Nutt, AIP Conf. Proc. 2008, 969, 656; b) J. Salvador, J. Yang, X. Shi, H. Wang, A. Wereszczak, H. Kong, C. Uher, Philos. Mag. 2009, 89, 1517; c) A. A. Wereszczak, M. E. Ragan, K. T. Strong, P. J. Ritt, H. Wang, J. R. Salvador, J. Yang, in Advanced Materials for Sustainable Developments, Wiley, Hoboken, USA 2010, p. 49; d) G. Rogl, P. Rogl, Sci. Adv. Mater. 2011, 3, 517; e) B. Duan, P. Zhai, P. Wen, S. Zhang, L. Liu, Q. Zhang, Scripta Mater. 2012, 67, 372; f) J. Eilertsen, M. A. Subramanian, J. J. Kruzic, J. Alloys Compd. 2013, 552, 492.

[25] L. Zhang, G. Rogl, A. Grytsiv, S. Puchegger, J. Koppensteiner, F. Spieckermann, H. Kabelka, M. Reinecker, P. Rogl, W. Schranz, M. Zehetbauer, M. A. Carpenter, Mater. Sci. Eng. B 2010, 170, 26.

[26] a) F. Ren, E. D. Case, E. J. Timm, H. J. Schock, J. Alloys Compd. 2008, 455, 340; b) F. Ren, E. Case, E. Timm, M. Jacobs, H. Schock, Phil. Mag. Lett. 2006, 86, 673; c) J. E. Ni, E. D. Case, J. Electron. Mater. 2013, 42, 1382.

[27] R. D. Schmidt, E. D. Case, G. J. Lehr, D. T. Morelli, Intermetallics 2013, 35, 15.

[28] J. Ma, S. Firdosy, R. Kaner, J. P. Fleurial, V. Ravi, J. Mater. Sci. 2014, 49, 1150.

[29] a) N. Satyala, J. S. Krasinski, D. Vashaee, Acta Mater. 2014, 74, 141; b) R. D. Schmidt, E. D. Case, J. Giles, J. E. Ni, T. P. Hogan, J. Electron. Mater. 2012, 41, 1210.
[30] a) Y. Gelbstein, G. Gotesman, Y. Lishzinker, Z. Dashevsky, M. P. Dariel, Scripta Mater. 2008, 58, 251; b) D. Vasilevskiy, R. Masut, S. Turenne, J. Electron. Mater. 2012, 41, 1057; c) J. E. Ni, E. D. Case, R. D. Schmidt, C. I. Wu, T. P. Hogan, R. M. Trejo, E. L. Curzio, M. G. Kanatzidis, Philos. Mag. 2013, 93, 4412.

[31] D. Kenfaui, G. Bonnefont, D. Chateigner, G. Fantozzi, M. Gomina, J. G. Noudem, Mater. Res. Bull. 2010, 45, 1240.

[32] Y. Xiao, J. Yang, G. Li, M. Liu, L. Fu, Y. Luo, W. Li, J. Peng, Intermetallics 2014, 50, 20.

[33] a) A. A. Wereszczak, T. P. Kirkland, O. M. Jadaan, H. Wang, in Advances in Electronic Ceramics II, Wiley, Hoboken, USA 2010, p. 131; b) Y. Zheng, H. Xie, S. Shu, Y. Yan, H. Li, X. Tang, J. Electron. Mater. 2014, 43, 2017.

[34] F. Ren, H. Wang, P. A. Menchhofer, J. O. Kiggans, Appl. Phys. Lett. 2013, 103, 221907.

[35] X. Fan, E. D. Case, X. Lu, D. T. Morelli, J. Mater. Sci. 2013, 48, 7540.

[36] M. S. Song, S. M. Choi, W. S. Seo, J. Moon, K. W. Jang, J. Korean Phys. Soc. 2012, 60, 1735.

[37] J. R. Salvador, J. Yang, A. A. Wereszczak, H. Wang, J. Y. Cho, Sci. Adv. Mater. 2011, 3, 577.

[38] O. M. Jadaan, A. A. Wereszczak, in Corrosion, Wear, Fatigue, and Reliability of Ceramics: Ceramic Engineering and Science Proceedings, Wiley, Hoboken, USA 2009, p. 156.

[39] J. J. Shen, T. J. Zhu, X. B. Zhao, S. N. Zhang, S. H. Yang, Z. Z. Yin, Energ. Environ. Sci. 2010, 3, 1519.

[40] a) T. Zhu, Z. Xu, J. He, J. Shen, S. Zhu, L. Hu, T. M. Tritt, X. Zhao, J. Mater. Chem. A 2013, 1, 11589; b) J. Li, Q. Tan, J. F. Li, D. W. Liu, F. Li, Z. Y. Li, M. Zou, K. Wang, Adv. Funct. Mater. 2013, 23, 4317.

[41] L. P. Hu, T. J. Zhu, Y. G. Wang, H. H. Xie, Z. J. Xu, X. B. Zhao, NPG Asia Mater. 2014, 6, e88.

[42] a) X. Su, H. Li, Y. Yan, H. Chi, X. Tang, Q. Zhang, C. Uher, J. Mater Chem. 2012, 22, 15628; b) W. Liu, X. Tang, H. Li, J. Sharp, X. Zhou, C. Uher, Chem. Mater. 2011, 23, 5256.

[43] X. Tang, W. Xie, H. Li, W. Zhao, Q. Zhang, M. Niino, Appl. Phys. Lett. 2007, 90, 012102.

[44] H. J. Goldsmid, Introduction to Thermoelectricity, Vol. 121, Springer, Berlin, Germany 2009.

[45] H. Goldsmid, R. Douglas, Br. J. Appl. Phys. 1954, 5, 386

[46] A. Joffe, L. Stil'bans, Rep. Prog. Phys. 1959, 22, 167.

[47] V. M. Prokhorov, G. I. Pivovarov, Ultrasonics 2011, 51, 715.

[48] a) J. Haines, J. Léger, G. Bocquillon, Annu. Rev. Mater. Res. 2001, 31, 1; b) S. F. Pugh, Philos. Mag. 1954, 45, 823.

[49] J. B. Wachtman, W. R. Cannon, M. J. Matthewson, Mechanical properties of ceramics, Wiley, Hoboken, USA 2009.

[50] M. K. Habibi, M. Gupta, S. P. Joshi, Mater. Sci. Eng. A 2012, 556, 855.

[51] S. Wiederhorn, Annu. Rev. Mater. Sci. 1984, 14, 373.

[52] B. Lawn, Fracture of brittle solids, Cambridge University Press, New York, NJ, USA 1993.

[53] E. D. Case, in Modules, Systems, and Applications in Thermoelectrics, CRC Press, Boca Raton, FL, USA 2012.

[54] M. A. Meyers, K. K. Chawla, Mechanical Behavior of Materials, Cambridge University Press, Cambridge, UK 2009.

[55] X. Chen, H. D. Zhou, A. Kiswandhi, I. Miotkowski, Y. P. Chen, P. A. Sharma, A. L. Lima Sharma, M. A. Hekmaty, D. Smirnov, Z. Jiang, Appl. Phys. Lett. 2011, 99, 261912.

[56] L. Pavlova, Y. I. Shtern, R. Mironov, High Temp. 2011, 49, 369.

[57] H. M. Ledbetter, N. V. Frederick, M. W. Austin, J. Appl. Phys. 1980 $51,305$.

[58] Z. Guan, Z. Zhang, J. Jiao, Physical Properties of Inorganic Materials, Publishing House of Tsinghua University, Beijing, P.R. China 1992. 